\title{
Escrituras contemporáneas y procesos de subjetivación política-juvenil. Reflexiones y desafíos para una pedagogía de la escritura en el contexto educativo
}

\author{
Contemporary writing and subjectivity processes in youngsters. \\ Reflections and challenges for writing teaching in educational contexts \\ Escritas contemporâneas e processos de subjetivação política-juvenil. \\ Reflexões e desafios para uma pedagogia da escrita no contexto educativo
}

Mónica María Bermúdez G.1

\section{Resumen}

El presente artículo propone un acercamiento a las relaciones entre escrituras digitales y procesos de subjetivación política, a partir de información suministrada (biografías tecnológicas, entrevista en profundidad y escrituras digitales compartidas) por algunos jóvenes que hacen parte del objeto de estudio de una investigación en curso. A partir del planteamiento sobre si antes la escritura era un proceso subjetivante que conducía a la reflexión, el autocontrol y la meditación privada, condiciones necesarias para la visibilización del ciudadano en el espacio público, es necesario preguntarse cómo hoy las escrituras digitales — con sus particularidadeslogran subjetivar políticamente a los jóvenes que cotidianamente las producen. En el análisis se hace énfasis en la pregunta por las subjetividades políticas que devienen, los lenguajes múltiples de escritura construidos y las formas de expresión en los entornos digitales. Lo anterior permite tensionar y (re)significar una pedagogía de la escritura en el contexto educativo, con el fin de enlazar una apropiación subjetiva actual y una intencionalidad formativa de las prácticas de enseñanza.

Palabras clave

escrituras digitales; modos de subjetivación política; subjetividades juveniles; escuela y pedagogía de la escritura

Abstract

This paper takes a close look at the connections involved in the production of digital writings and the processes of political subjectivity based on the information provided by a number of youngsters participating in an ongoing research study (digital biographies, in-depth interviews and shared digital writings). It can be stated that, if writing has always been a subjectivity process that leads to reflection, self-control and private meditation - conditions that are required for the recognition of a citizen in the public arena - it is pertinent to ask ourselves questions regarding how digital writing (with its peculiarities) can make an impact in the political subjectivity of the young people that produce them. The analysis emphasizes the question about political subjectivities that are derived from these kinds of interactions, the multiple writing languages that have arisen and the different expression that take form in digital environments. The product of this research allows us to strain and give a new meaning to writing teaching in the educational context in order to reflect the current subjectivity and a formative intention of teaching practices.

Keywords

digital writing; political subjectivity; subjectivity in youngsters; writing and pedagogical teaching

\section{Resumo}

0 presente artigo propõe uma aproximação às relações entre escritas digitais e processos de subjetivação política, a partir de informação subministrada (biografias tecnológicas, entrevista em profundidade e escritas digitais compartilhadas) por alguns jovens que fazem parte do objeto de estudo de uma pesquisa em curso. A partir da abordagem sobre se a escrita foi um processo subjetivante que levava à reflexão, o autocontrole e a meditação privada, condições necessárias para a visibilização do cidadão no espaço público, é necessário perguntar como hoje as escritas digitais - com suas particularidades - conseguem subjetivar politicamente os jovens que as produzem a diário. A análise da ênfase à pergunta pelas subjetividades políticas que surgem, as linguagens múltiplas de escrita construídas e as formas de expressão nos ambientes digitais. 0 anterior permite (re)significar uma pedagogia da escrita no contexto educativo, visando vincular uma apropriação subjetiva atual e uma intencionalidade formativa das práticas de ensino.

Palavras chave

escritas digitais; modos de subjetivação política; subjetividades juvenis; escola e pedagogia da escrita

Artículo recibido el 29 de mayo de 2016 y aprobado el 21 de diciembre de 2016

1 Estudiante del Doctorado Interinstitucional en el grupo Educación y Cultura Política de la Universidad Pedagógica Nacional, Bogotá, Colombia. Profesora del Departamento de Formación de la Pontificia Universidad Javeriana, Bogotá, Colombia. Correo electrónico: mmbermudez@javeriana.edu.co 


\section{A manera de contexto}

Como ya se ha analizado en otro escrito (Bermúdez, 2015a), la producción subjetiva se enlaza con intereses políticos y culturales de cada momento sociohistórico. Son las estructuras biopolíticas las que originan en los sujetos los significados identitarios de los territorios, los discursos, las prácticas y las representaciones de mundo como extensiones de lo que se requiere para el logro de determinados fines (Mejía, 2004). Un ejemplo de esto es lo que sucedía en la sociedad moderna: el sujeto político (idealizado) tenía que ser obediente, disciplinado, dócil y productivo, además de blanco, varón, heterosexual e ilustrado (Castro-Gómez, 2009; Escobar, 2012). Y para lograrlo, el Estado-nación se valió de algunas herramientas, como los manuales de buen comportamiento y las prácticas escriturales en solitario, condiciones para fortalecer el juicio y la opinión pública, tan necesarios para la supervivencia de la política estatal y para la visibilización del ciudadano moderno (González, 1994).

La tecnología de la escritura construida en el encierro cumplió funciones disciplinarias sobre el cuerpo y la mente para conducir a la docilidad y la productividad "servil" de las personas. En la actualidad ya no son necesarios el recogimiento y la introspección fabricados por las prácticas escriturales (Sibilia, 2008). Hoy, "en tiempos de globalización el capitalismo exacerba una sociedad de control y requiere otro tipo de sujeción: más que la producción [y domesticación] de los cuerpos de los trabajadores interesa la seducción de las mentes de los consumidores" (Escobar, 2012, p. 89). Esto se logra, principalmente, a través de los nuevos dispositivos de poder: las tecnologías digitales o máquinas informáticas, como las llama Lazzarato (2006).

A partir de ellas se generan beneficios económicos, pues con la hiperconexión de los "usuarios" las empresas de software logran incrementar ganancias, producir nuevas aplicaciones y seducir con la oferta constante de nuevos productos. La sujeción se produce por medio de la fascinación de las tecnologías con la promesa de felicidad, estatus, agencia y éxito personal, con lo cual se cimentan formas de consumo. Un efecto pharmakón remedio-veneno, como lo ha analizado Rueda (2012), tiene lugar en estos contextos y en las producciones subjetivas que allí se despliegan. Es decir, en cada compra e interacción tecnológica que se realice se nutren el mercado y la industria del software (efecto veneno), pero cuando se logra comunicar, por ejemplo, una indignación y esta se socializa a través de las redes sociales-digitales, es factible la consecución de lazos de solidaridad, cooperación y posible reparación de los hechos nocivos (efecto remedio).

Desde estas nuevas condiciones sociotécnicas, y teniendo en cuenta que las tecnologías digitales son los vasos comunicantes del actual capitalismo, nos interesa hacer un acercamiento a las relaciones entre escrituras digitales y procesos de subjetivación política, a partir de información suministrada (biografías tecnológicas, entrevistas a profundidad y escrituras digitales compartidas) por algunos jóvenes que hacen parte del objeto de estudio de una investigación en curso ${ }^{2}$. De entrada podemos plantear que, si antes la escritura era un proceso subjetivante que conducía a la reflexión, el autocontrol y la meditación privada, condiciones desde las cuales se deseaba afectar la relación con el espacio público, es necesario preguntarse cómo hoy las escrituras digitales logran subjetivar políticamente a jóvenes que cotidianamente las producen. En este sentido, no se trata de hacer una apología de los dispositivos tecnológicos, con lo cual se desconocerían otros escenarios de experiencia que tienen lugar en la vida juvenil. Se trata, más bien, de hacer énfasis en la pregunta por las subjetividades políticas que devienen, los lenguajes múltiples de escritura que se construyen y las distintas formas de expresión en los entornos digitales.

Las escrituras producidas en tales espacios nos permitirán comprender los meandros por donde hoy discurre la subjetividad política-juvenil, pues la escritura es un mostrarse, un hacerse ver y un hacer aparecer el propio rostro ante el otro (Foucault, 1999). En estas escrituras habrá "denominaciones

2 Se trata de la tesis doctoral "Escrituras digitales y modos de subjetivación política. Proximidades desde la subjetividad juvenil contemporánea". 
dormidas, significaciones ocultas, escondidas, que la acompañan como un caudal lleno de resonancias que siempre será posible despertar, clarificar, devolver a la luz del mundo" (Rodríguez, 2000, p. 15). Esto nos permitirá leer las transiciones con respecto a una escritura moderna, pero sobre todo nos dejará ver las relaciones de una escritura abreviada, abierta y flexible con unas maneras de ser que devienen con otros y que desean construirse políticamente. Por ello, intentamos observar a jóvenes que no necesariamente estén vinculados a organizaciones políticas o movimientos sociales, sino que constituyen esa política en la cotidianidad, en el día a día, donde la filia, la amistad y el afecto son una manera de vivir y producir una política particular (Gómez, 2010; Rueda, 2011).

Para cerrar este apartado, reiteramos que las relaciones entre escrituras digitales y procesos de subjetivación política-juvenil pueden permitirnos configurar una pedagogía de la escritura en la que el uso (rebelde) de tecnologías digitales sea un propósito clave para la ampliación de proyectos escriturales que contribuyan a la toma de conciencia por parte de los educandos, en términos de develar los fines y los mecanismos del capitalismo globalizado, $y$, en consecuencia, subvertir el orden impuesto con capacidad de agencia y resistencia a partir de la producción de diversos tipos de textos en marcos de enunciación tanto colectivos como individuales. Esto lo vemos como posibilidad para enlazar la apropiación subjetiva (escrituras digitales) de los jóvenes contemporáneos con la intencionalidad formativa de las prácticas de enseñanza en el contexto educativo.

El artículo está organizado en cuatro apartados. En el primero abordaremos los supuestos teóricos que el presente texto asume en cuanto a procesos de subjetivación política y escrituras digitales. En el segundo daremos cuenta de la metodología utilizada y de algunas técnicas de recolección de información, como las biografías tecnológicas, la entrevista en profundidad y las escrituras digitales compartidas. En el tercer apartado trabajaremos en algunas interpretaciones a partir de la información suministrada por dos jóvenes partícipes del estudio: Edward y Johanna. Por último, dejaremos planteadas algunas reflexiones para una pedagogía de la escritura, cuyo objetivo es desafiar su enseñanza en espacios educativos a partir de lo que la experiencia de estos jóvenes nos propone.

\section{Supuestos teóricos: procesos de subjetivación política y escrituras digitales}

Antes de abordar conceptualmente las dos categorías más importantes del presente texto, quisiéramos plantear la significación que, a nuestro juicio, tiene hoy la producción de política. Hacerlo implica no formular sin más la definición y el concepto de subjetivación política y de escrituras digitales, sino esbozar las relaciones entre ellas, con el fin de dar cuenta de las comprensiones e interdependencias que, a partir de la experiencia política, las personas vienen configurando en sus espacios de creación individual y colectiva.

\section{La política contemporánea: malestares y potencias}

Las condiciones socioeconómicas actuales producen subjetividades en las que se arraigan creencias y acciones impregnadas por mecanismos subjetivantes articulados al mercado y al consumo, modos de ser que se confunden con las ilusiones y la aparente felicidad tras de las cuales se entrevé la falacia de la oferta como vivencia que hace suponer que es allí donde radica el sentido de la vida. Según Amador (2012), "la dinámica contemporánea del biopoder ya no solo se despliega mediante el encierro y la coerción, sino a través de atracciones mediadas por las imágenes y mundos de deseo que son ofrecidos por la publicidad y el mercado" (p. 19).

Es indudable que estos cambios socioeconómicos configuran procesos de subjetivación que producen experiencias, saberes y narrativas que se expresan desde los mismos intereses que el sistema promueve, o bien desde las interpelaciones que los mismos sujetos construyen como fugas y creaciones de sí. Sobre estos últimos casos, nos interesa en particular posicionar la significación de política que se encuentra en la base de la investigación en curso, ya que una parte de estas experiencias se configura alrededor de las búsquedas desplegadas por las subjetividades: 
sueños, afectos y proyectos que se forjan contra un discurso homogeneizador que construye acciones y formas de ser globalizadas. Se trata de prácticas políticas diversas, producidas en ámbitos individuales y colectivos, pero en las que mayormente se desea construir la sociedad "desde abajo", es decir, una sociedad activa en el espacio público, conforme a los intereses coyunturales, con perspectivas flexibles. Los jóvenes se involucran en causas a través de las cuales se expresan libremente, producen lenguajes diversos (icónicos, musicales, hipertextuales), hacen redes y experimentan el cuerpo como territorio (Muñoz, 2007; Bermúdez, 2014).

Hablamos de un reconocimiento de la diferencia y la creación de mundos posibles como procesos de subjetivación producidos por la experimentación que brota de la intención de construir la política como acontecimiento, es decir, como una producción de novedad, de algo que no estaba dado, que surge en el acto, que es realización, pero también posibilidad (Lazzarato, 2006). Lo que sigue es un acercamiento conceptual a los procesos de subjetivación política. Si bien podemos denominar la subjetividad como una noción inherente a la política, resulta crucial especificarla, ya que nos interesa buscar las expresiones políticas de las subjetivaciones juveniles a partir de las escrituras digitales, las cuales son fundamentalmente relacionales-alterdirigidas, si se prefiere.

\section{Subjetivaciones políticas y tecnologías digitales}

La política deviene hoy con diversos sentidos, intenciones y prácticas producidos singular y colectivamente, lo que nos permite abordar procesos de configuración política que producen las personas en relación con márgenes de dominio globalizantes y locales, de los cuales es necesario sustraerse. Dichos procesos aluden a subjetivaciones, es decir, a acciones o prácticas que las personas crean sobre sí, con el fin de producir transformaciones y experiencias alejadas de la dominación. Se subjetivan, buscan, se mueven y se desplazan hacia otras situaciones en las que se reconocen a sí mismas como potencia y posibilidad.
Dichas relaciones o subjetivaciones son producidas no en el plano del sujeto consigo mismo, en una especie de autodeterminación, sino que, a la vez que se configuran contingencias de liberación para sí, lo hacen con otros, en interacciones permanentes, en una creación de fugas ligadas a un deseo de querer ser otro-diferente, para desviar las sujeciones que un "extraño" pretende ejercer (Deleuze, 2006), todo ello en tiempo y espacio presentes. Al decir de Foucault (1999):

[...] abren un campo de experiencia en el que el sujeto y el objeto [u otro sujeto] no se constituyen uno y otro sino bajo ciertas condiciones pero en las que, a su vez, no dejan de modificarse el uno al otro, y por tanto, de modificar ese mismo campo de experiencia. (p. 366).

De este modo, la subjetivación resulta inherentemente política, pues deviene en un campo relacional bajo una doble afectación: para el sí mismo y para los otros, sin que con ello se establezcan límites de llegada, partida o correspondencia, sino una imbricación permanente. No hay un antes o un después, solo un durante, y ahí permanecen todos - el yo, ellos, nosotros-, en un tránsito, siempre en suspenso. De ahí que deseamos ver en la subjetivación política el reconocimiento de las ambigüedades y potencias como cruces de la significación de la política contemporánea - tal como lo expusimos atrás-, en la que se encuentran formas diversas y plurales - no esenciales - de tramitar la vida y las resistencias a las que nos convoca el mundo actual.

Agregado a lo anterior, deseamos ver una subjetivación política que se comprende, justamente, como construcción "de relaciones externas, de condiciones, circunstancias y modalidades exteriores al sujeto" (Tassin, 2012, p. 38). Esto nos posibilita desprender la subjetividad política del espacio íntimo, de interioridad e introspección, para abordarla como "un modo de ser y estar en el mundo, como una piel subjetiva que vive la experiencia de encuentro/desencuentro con los otros que plantea la vida en común" (Bonvillani, 2014, p. 83), y que logra constituirse con y desde afuera, en prácticas sociales nómadas, errantes, a través de las cuales la 
subjetividad se expresa en una lucha, en un debate entre dispositivos, estructuras, sujeciones, deseos y sueños.

La subjetivación política concebida así nos lleva al deseo investigativo de querer explorarla en los actuales dispositivos de poder, es decir, en las tecnologías digitales o máquinas de expresión. Espacios como redes sociales, páginas web, blogs, wikis, correos electrónicos y documentos hipertextuales, entre otros, se inscriben en las realizaciones humanas, en la agencia y posibilidad que las personas, según las significaciones que construyen, incorporan en su devenir existencial.

A nuestro juicio, cada interacción digital se convierte en una experimentación de lectura y escritura narrativa, pues al moverse en estructuras que no están soportadas por la secuencialidad y linealidad, la posibilidad de transitar por nodos, flujos de información, videos, imágenes, páginas web, entre muchos más, se produce una experiencia singular, emanada de la agencia subjetiva. Esta nueva lectio (De Certeau, 1985) "no corresponde ni a los gestos ni a las operaciones intelectuales del libro impreso" (Chartier, 2007, p. 13), más bien se vincula con un arte de crear mundos diversos (Jenkins, 2008; Amador, 2012), plurales y en sintonía con identidades que no están formadas, sino que devienen, que están siendo. De ahí que las escrituras digitales como expresiones de la producción subjetiva actual nos permitan visibilizar modos de subjetivación política que configuran jóvenes contemporáneos en sus interacciones tecnomediadas.

\section{Escrituras digitales}

Las variaciones que hoy tienen lugar en el lenguaje por cuenta de las actuales tecnologías se manifiestan claramente a través de las escrituras que fluyen de modo constante en los espacios tecnomediados. Tales escrituras se pueden denominar vernáculas, es decir, escrituras que se desprenden de la voluntad individual y no están reguladas por instituciones sociales (Cassany, 2012). Son, ante todo, producciones escritas vinculadas con el día a día, con la emergencia subjetiva y con la inmediatez de lo que se quiere plasmar de forma escrita. Algunos ejemplos son los mensajes íntimos, los apuntes personales, los grafitis, las conversaciones en un chat, los comentarios en las redes sociales-digitales, los tweets, entre otros.

Las escrituras digitales de carácter vernáculo pueden estar afectando los modos de subjetivación política, pues a la vez que los sujetos producen dichas escrituras, estas producen un sujeto que se visibiliza desde la exterioridad, desde la espectacularización de su yo (Sibilia, 2008), desde un deseo por comunicar lo que piensa en el instante, $y$ por una alteridad que parece fortalecerse con aceptaciones que otros hacen a partir de obras digitales que se llevan a cabo en redes sociales. Dichas escrituras tienen una organización textual no secuencial en su narrativa y a través de la cual se integran distintas significaciones. Es un producto que no cesa de comenzar y que, por tanto, nunca culmina: se sigue elaborando, (re)haciendo, y sus construcciones, que se tornan en significaciones, desprovistas en muchas ocasiones de palabra escrita, se trastocan con otros modos de expresión y narración propios de una subjetividad que intenta revelarse mediante una huella o marca de lo que se produce digitalmente.

Con la caracterización de estas escrituras contemporáneas deseamos acercarnos a las acciones o prácticas políticas que configuran algunos jóvenes, en atención a las pasiones que de la condición humana se derivan y a las relaciones de alteridad que constituyen la existencia, mediadas, en parte, por la producción de lenguajes que desbordan la secuencialidad y ordenación de la palabra escrita, y que se incorporan a la convergencia de diversos modos de hacer en los que se juntan sonidos, imágenes, música y videos, para expresar y significar actos comunicativos que se cargan social y subjetivamente.

A continuación presentamos la metodología y las técnicas de recolección de información que utilizamos con el fin de explorar las relaciones entre escrituras digitales y procesos de subjetivación política. 


\section{Acercamiento metodológico}

Para llevar a cabo nuestra propuesta, optamos por una perspectiva cualitativa, pues nos permite aproximarnos a los sentidos que los sujetos otorgan a fenómenos sociales, a las relaciones de las personas con otras, con los contextos y con la materialidad que hace parte del paisaje experiencial construido por ellas. Esta metodología acoge las subjetividades individuales y colectivas en su forma singular, los sentidos y prácticas comunicativas en sus espacios cotidianos, en los que se despliegan maneras de ser cargadas de significados culturales, políticos, siempre en diálogo con diversos momentos de la existencia. Optar por un enfoque cualitativo es reconocer la diferencia y la significación que cada quien imprime a su propia vida. Esto, a su vez, le permite al investigador configurar la intención discursiva más potente que cualquier fenómeno estudiado puede otorgar: la interpretación. La práctica discursiva de producción de pensamiento y de diálogo con los datos lleva justamente a descubrir y crear nuevos modos de pensar, de ver y de apreciar.

Agregado a lo anterior, nos interesó poner énfasis en la etnografía virtual y multisituada como enfoque que nos ayudaría a desentrañar los meandros y alteridades de un sujeto que deviene en la interacción con las tecnologías digitales. Como se ha analizado en otro trabajo (Bermúdez, 2015b), se hace necesaria una exploración de carácter plural, es decir, que no resulta suficiente la mirada sobre una única interacción, sino que los múltiples espacios de producción subjetiva resultan implicados en significaciones distintas y con puntos de vista que sustentan, de algún modo, las decisiones en la vida de los jóvenes. Miremos las finalidades de cada una.

\section{Etnografía virtual}

Según Hine (2002), la etnografía de Internet permite observar con detalle las formas en que se experimenta el uso de una tecnología, en razón de las concepciones que se tienen, por un lado, de tecnologías digitales o de Internet como espacios de producción subjetiva, y, por otro, de las relaciones de los sujetos con los dispositivos que usan y apropian en sus prácticas comunicativas cotidianas. Mayormente, se opta por una etnografía de este tipo para explorar lo que pasa en los espacios digitales, pues se pretende describir y dar cuenta de fenómenos sociotécnicos con el fin de interpretar los cambios y las transformaciones que vienen sucediendo en las personas cuando usan intensamente redes sociales, blogs o páginas web. Analizar qué se produce, para qué, por qué, en qué situaciones, cuáles interacciones se configuran, qué luchas políticas se gestionan y con qué lenguajes, entre otras cuestiones, es la intención de la descripción y, en consecuencia, de la comprensión de las realidades sociodigitales estudiadas.

\section{Etnografía multisituada}

Este tipo de etnografía fue propuesta por Marcus (2001) para dar cuenta de los sentidos que construyen las personas en diversos lugares. Nuevamente, la intención es encontrar relaciones que fortalezcan la descripción detallada de las prácticas y significados de los sujetos, y con ello las comprensiones de las realidades sociales diversas y múltiples que se producen en la sociedad. Recurrimos a las estrategias de mapeo propuestas por este autor para descubrir en los actores sus narrativas, sus prácticas y sus relaciones llevadas a cabo en espacios tanto digitales como físicos. Tales estrategias se detallan a continuación:

- Seguir a los sujetos: se trató de estar y vivir con los jóvenes en los espacios que habitan, aquellos que gozan de significación y deseo para ellos, y desde los cuales se desarrolla mayormente su existencia.

- Seguir los objetos: se trató de analizar tanto los diferentes dispositivos tecnológicos con los cuales se relacionan los jóvenes, como las razones que tienen para elegirlos y usarlos, y las prácticas que allí realizan como formas de apropiación.

- Seguir las metáforas: para llevar a cabo esta estrategia, acudimos a las escrituras digitales como aquellas producciones en las que se visibilizan diversos juegos del lenguaje, con los 
cuales los jóvenes expresan modos de sentir y de subjetivarse políticamente.

- Seguir la vida o la biografía: acudimos a los relatos de vida para visibilizar las intenciones, los acontecimientos y las razones que tramitan como formas de significar la existencia tanto consigo mismos como con los demás.

Con las estrategias epistemológicas e investigativas anteriores, decidimos trabajar con tres técnicas de recolección de información para develar e interpretar algunas relaciones producidas entre escrituras digitales y modos de subjetivación política. Acudimos entonces a la construcción de biografías tecnológicas, las entrevistas en profundidad y los análisis de escrituras digitales. Vale decir en este punto que las interpretaciones que más adelante expondremos se derivan de la información articulada o integrada que cada una de estas técnicas nos permitió elaborar; esto, a su vez, nos permite recurrir a la triangulación de fuentes como mecanismo de validez de la investigación cualitativa. De igual modo, es importante recordar que lo hecho hasta ahora es un acercamiento parcial derivado del trabajo con dos de los jóvenes partícipes del estudio, por tanto, no deseamos hacer generalizaciones, sino descripciones comprensivas de la experiencia subjetiva juvenil en espacios tecnomediados.

A continuación describiremos, grosso modo, los significados que tienen estas técnicas y su impronta en el desarrollo de la intención propuesta.

- Biografías tecnológicas: se abordan como la producción de un relato de vida elaborado por un sujeto que decide participar en un propósito comunicativo propuesto por alguien que desea investigar sobre determinado tema, o bien indagar o explorar situaciones de vida particulares, para singularizar la vida que ha transcurrido en un tiempo y espacio determinados (Rueda y Calonje, 2014). El sujeto evoca, construye límites y cuenta aquello que resulta esencial tanto para sí como para un otro posible. El valor biográfico organiza y ordena las vivencias y la narración de la propia vida, otorgándole comprensión, visión y expresión (Arfuch, 2002).
En nuestro caso, nos interesaba que el relato estuviera producido en el marco de los eventos o las experiencias en las que el uso y la apropiación de tecnologías digitales han ocupado un lugar preponderante. El relato biográfico-tecnológico producido por los jóvenes fue de tipo oral y estuvo provocado por preguntas de carácter general. Sobre estas se plantearon algunos núcleos temáticos, como: (i) contexto histórico: adquisición y usos iniciales; (ii) familia y usos; (iii) tiempo y dedicación; (iv) tecnologías digitales: preferencias entre una y otras, decisiones, aplicaciones privilegiadas; (v) relaciones entre espacios online y offline; (vi) actividades en espacios digitales; y (vii) experiencias de escritura digital.

- Entrevista en profundidad: se concibe como una narración conversacional producida por dos o más sujetos (Delgado y Gutiérrez, 1995). Dicha conversación se configura a partir de preguntas que tienen la intención de profundizar en un hecho, un evento o unos motivos, sobre los cuales es necesario regresar en nombre de la comprensión que se desea conseguir. Por lo general, la entrevista en profundidad se produce en un primer encuentro, luego del cual, y de la relectura de lo vivido y escuchado, nacen otras preguntas que amplían la indagación.

En nuestro caso, por ejemplo, la entrevista en profundidad surgió de los relatos biográficostecnológicos. Fue necesario, en términos de la exploración que estamos llevando a cabo, hacer otras preguntas que concretaran razones, gustos, intereses, decisiones y deseos de los jóvenes en sus interacciones digitales. Tales preguntas no tuvieron un carácter tan abierto como las sugeridas para el relato de vida, sino que fueron más concretas y estuvieron referidas a circunstancias propias de los nuevos entornos: saturación de información, operaciones de escritura digital, función de la lectura y la escritura en intenciones personales, prácticas comunicativas cotidianas, entre otros aspectos. 
- Escrituras digitales compartidas: son las producidas por los jóvenes en sus espacios digitales. Durante cuatro meses nos compartieron escrituras que elaboran con intensidad en redes sociales como Facebook y Whatsapp. Quisimos tener una observación más directa de las interacciones y escrituras digitales realizadas, pero infortunadamente no fue posible, pues los jóvenes no nos aceptaron en su red de amigos de Facebook y tampoco aceptaron tener contacto a través de Whatsapp. Las justificaciones que esgrimieron se referían a mi rol como profesora y a la comunicación íntima que diariamente construyen con sus amigos. Les pedimos entonces que nos compartieran aquellas escrituras que podríamos ver sin que ellos se sintieran incómodos. Así, semanalmente, nos enviaron pantallazos (entre 25 y 30 ) de sus escrituras producidas en Facebook y Whatsapp.

A continuación haremos algunas interpretaciones derivadas de la información suministrada.

\section{Entre la escritura digital y la subjetivación política. Algunas visibilidades}

Las interpretaciones que veremos a continuación (relaciones entre escrituras digitales y subjetivaciones políticas) surgieron de la relectura que se hizo de la información producida por medio de las tres técnicas mencionadas. De igual modo, dicho proceso no se elaboró desde un sentido singularunitario, sino en una especie de tejido a partir de una lectura intertextual. Esto posibilitó que las escrituras digitales se interpretaran de la mano con lo dicho en la entrevista o con comentarios biográficos. Así mismo, los datos biográficos se relacionaron con las escrituras y las respuestas de la entrevista en profundidad.

Lo que veremos es un anticipo del trabajo de análisis que venimos realizando. A partir de lo que Johanna y Edward nos proporcionaron, intentaremos tejer los movimientos, desplazamientos y creaciones que estos jóvenes realizan en sus espacios digitales, y en los que la escritura digital materializa las vivencias de un yo. Johanna y Edward son estudiantes de una universidad privada de Bogotá, y tienen 25 y 23 años, respectivamente. Johanna es de Bucaramanga y estudia Pedagogía Infantil. Edward es de Bogotá y estudia Arquitectura. Ambos provienen de un estrato socioeconómico medioalto, y hacen parte de esta indagación porque usan intensamente tecnologías digitales. Su vida, según ellos, se reduce a poco cuando no están conectados.

\section{Primera interpretación: la escritura biográfica como inicio de una subjetivación política}

Una reiteración discursiva que encontramos en lo dicho tanto por Johanna como por Edward se refiere a los intereses, fines y búsquedas que incorporan al uso y a las interacciones digitales que llevan a cabo. Se expresan experiencias en las que un yo es el que produce la sintaxis de lo que se hace en los espacios digitales, en las conversaciones $y$ en acciones diversas. Encuentran, por ejemplo, en Facebook y Whatsapp un lugar para compartir e interactuar con otras informaciones, imágenes, videos, los cuales se anudan a un interés subjetivo, a unas representaciones que tienen sobre la vida, que se socializan espaciadas, por momentos, $y$ que no son continuas sino esporádicas, pequeñas y anudadas, por lo general, a un estado de ánimo:

Todo el tiempo estoy conectada, no hacerlo es como estar aburrida, o incluso aburrirme más. Converso, miro cosas, hablo con mis amigos, me comunico con mi familia, que vive en Bucaramanga, con mi novio, que no lo dejan usar celular en el trabajo, pero por el chat de Gmail nos hablamos. (Johanna, 25 años).

Mientras que Edward dice:

Todo lo planeo a través de la tecnología, comunicarme para poder llegar a un punto de encuentro, para planear alguna cita o algo, siempre uso la tecnología. También para compartir fotos y todo esto, pues también es bastante personal. Lo primero, desde la alarma del celular como forma de comenzar, cuando me estoy alistando la música es crucial, ya después reviso si tengo correos o algo para planear el día o alguna persona que tengo que 
encontrarme ese día y ya. Después cuando llego a la universidad de pronto en alguna clase lo miro para buscar alguna información, para la hora del almuerzo pues para ver con quién encontrarme para almorzar, en la noche llego a mi casa e ingreso a Facebook, escucho música, busco información, noticias, como entretenimiento, pues ya en la noche cuando estoy trabajando siempre mantengo algunas redes abiertas para buscar como referentes, información, para comunicarme con alguien, siempre está presente en todo momento. (Edward, 23 años).

Los deseos, vivencias e intereses de estos jóvenes se materializan a través de las escrituras producidas en sus dispositivos digitales. Se trata de escrituras que, al estilo de Serres (2013), se dejan como huellas por donde pasan, que son incidentales, abiertas, aprobatorias, afectivas, rabiosas: como lo expresaba Edward, son escrituras de "desparche", es decir, que surgen de lo que se va haciendo en el instante, para luego modificar situaciones comunicativas, emocionales, existenciales y amistosas: lo biográfico como posibilidad de ser con otros, en una "fuerza deseante [que] vincula la singularidad con relaciones expansivas" (Piedrahita, 2015, p. 49).

Frente a esta condición biográfica, tenemos dos cuestiones. La primera es que este interés de los jóvenes por buscar(se) y relatar(se) puede comprenderse como una de las sujeciones que efectúa el capitalismo actual: un proceso de personalización en el que lo más importante es ser uno mismo (Lipovestky, 2002); de ahí, la producción de escenarios biográficos como las actuales redes sociales-digitales que incitan a las personas a publicar sus sentires y acciones cotidianas de vida, todo con el fin de ser valorados y reconocidos a través de lo que se compra: viajes, ropa, productos de belleza, dispositivos tecnológicos, entre otros.

Los jóvenes de este estudio no son ajenos a ello, también compran y sucumben a las seducciones fabricadas por la publicidad y la hiperconexión de las redes sociales, solo que no se quedan ahí, en el mero consumo o sedentarismo existencial, lo cual los podría conducir a posibles operaciones autodestructivas, en las que la ansiedad, la violencia o las adicciones pueden aparecer (Piedrahita, 2015). Optan más bien por una reinvención de sí, por ser diferencia, y esto lo vemos en la sustracción que hacen a partir de la configuración de proyectos personales, en los que si bien parten de intereses propios (con ínfulas individuales), luego se tornan comunes a muchos con los que interactúan y comparten información. Además, tramitan vínculos con conocidos y no conocidos, realizan actividades en espacios online y offline y producciones como videos, fotografías y narrativas digitales, en las cuales se produce una política en la que, hoy más que nunca, se pone en juego la vida (Foucault, citado en Agamben, 2001, p. 16), lo que conlleva a manifestar de forma diversa la capacidad de agencia de los actores en sus proyectos de vida.

Una segunda cuestión es la definición de lo biográfico. A diferencia de la consideración que tenía en la sociedad moderna, hoy lo biográfico no se expresa en un orden secuencial y sistemático de hechos vividos por las personas, sino que, al igual que el tiempo actual, fragmentado y disperso, asimismo aparece la narrativa personal, algo incidental, anímica y variable según el estado de ánimo, lo cual se enlaza con escrituras que en ocasiones conviven con imágenes, sonidos y videos, en unas, con mensajes de voz, en otras, y con cadenas de frases lineales (Whatsapp, por ejemplo). Es una escritura que se arma de piezas, huellitas, como expresaba Serres (2013), obras compuestas de pedazos, al estilo de las colchas antiguas, con colores, tejidos e hilos diversos que producen a su vez una estética del afecto.

Así las cosas, abordar la producción de subjetivaciones políticas en estos espacios digitales implica reconocer la hegemonía digital que al interior de estos se emplaza. Como lo analizaron Corea y Lewkowitcz (2004), la velocidad, la hiperabundancia de información y la fragmentación de la comunicación son los dominios en donde se capturan las mentes y el deseo de los conectados; por esto, las resistencias como formas creativas (Foucault, 1996) son las producciones subjetivas que se sobreponen a tales rasgos y se opta por la construcción de proyectos subjetivos, a través de los que se logra desacelerar la saturación publicitaria, icónica, textual, de los ambientes digitales. 
Johanna encontró en sus actividades digitales la posibilidad de trabajo sobre la defensa y protección de los animales de la calle. Se unió a un grupo de cuidado y adopción de perros y gatos en Bogotá. Los integrantes, que en su mayoría no se conoce físicamente, se comprometen con la socialización de información sobre animales maltratados y con una comunicación dialógica que contribuya a tomar decisiones sobre problemas de enfermedad y abandono de estos:

Estoy metida en bastantes páginas de animalistas y de rescate, de fundaciones y eso, y uno, aunque no lo crea y aunque pues todos queremos el bien para los animales, pero es que a veces es una sola pelea entre opiniones normales, por ejemplo, ellos dicen "ay, sí, a ti te gustan los animales pero comes carne" entonces son como dilemas. Pero sí lucho por la protección de gatos y perros desamparados; tomo fotos cuando voy en el Transmilenio, las publico y de ahí comienza una conversación con todos los que hacemos parte de esta lucha. Cuando uno ayuda a compartir la información de los animalitos perdidos, o de que necesitan apoyo, o de cuando uno está donando, y no solo me ha pasado con gente $\mathrm{X}$ sino que con mis compañeras, que a veces encuentran a un animalito y dicen "ayúdanos a publicar y a rotar la información", entonces digamos que se hace para bien, compartir información que también le sirva a otras personas, no solamente ocio, sino como artículos o que le puedan servir a los demás. (Johanna, 25 años).

En el caso de Edward, la opción de su proyecto es por la vía de lo académico. Su carrera de arquitectura colma intereses, gustos y propósitos por medio de los cuales logra relacionarse con otros, seguir compañeros de otras universidades, conversar con expertos en el tema. Si bien esta opción hace parte de la condición biográfica como mecanismo de personalización de la que la formación hace parte - algunas veces-, la producción del proyecto de Edward tiene que ver con él, con sus anhelos y sentidos de vida. Sobre esto se va formando un común, un lazo social que contribuye al afianzamiento de lo que se quiere, y que se logra a partir de una comunicación colectiva que tiene a su vez un carácter hipertextual:
Sigo muchas páginas, referentes arquitectónicos, entonces siempre busco planos, algunas edificaciones, porque tengo bastante información, también para eventos, para consultar eventos de la semana, también tengo algunas noticias, datos curiosos, como que siempre, se me hace que Facebook es una buena plataforma de publicidad, como que es muy fácil enterarse y llegar a los puntos desde la misma. Uso el Messenger de Facebook, sí lo uso para lo académico y para lo afectivo, por ejemplo tengo varios grupos de las clases o de grupos de trabajo donde compartimos la información, donde mandamos trabajos a través de Facebook, archivos pequeños o links de páginas o también relaciones, entretenimiento. (Edward, 23 años).

Lo que Johanna y Edward muestran es que a los estímulos, la velocidad y la sobrecarga cognitiva les hacen frente con la configuración de un proyecto social y personal que reúne a otros, y a través del cual logran colectivizar las palabras, imágenes y prácticas comunicativas. Aquí escriben entre todos (Levy, 2007), lo cual a su vez subvierte el espíritu individualista impuesto en los nuevos escenarios biográficos (aunque no es para confiarse). De igual modo, estos jóvenes subvierten el estigma social que plantea que los jóvenes no escriben. En lo que vimos escriben muchísimo, claro, no lo hacen a la manera en que la sociedad moderna y aún la escuela contemporánea lo exige - textos largos, lineales y en gramáticas análogas ordenadas-, sino que lo hacen por elección y con una diversidad expresiva-técnica que sobrepasa a la palabra escrita.

Es necesario detenernos aquí en el concepto de escritura, el cual - y a nuestro juicio- se ajusta a una idea de vaso comunicante, que se produce, en primer lugar, por el deseo de estar conectado. Estos jóvenes no están pensando en cómo la escritura los puede producir subjetivamente, no se idealizan a través de esta, no están pensando en las implicaciones que puede tener para ellos. Piensan, al contrario, que escribir, como tal, es lo que les ayuda a sostener los trayectos configurados con los amigos, la familia, la academia, y a liberarse de la incertidumbre, la soledad y la inseguridad que produce el tiempo actual. Por esto, los jóvenes escriben a su manera: acomodándose 
según la situación, con palabras abreviadas, con imágenes, vivencial y emocionalmente.

Las escrituras digitales de estos jóvenes estarían convocando a la configuración de una conciencia flotante, o sensibilidad fluida, pues al disminuirse una vigilancia racional aparece "un estado elevado de percepción y receptividad [...] donde la imaginación y la afectividad tienen un lugar preponderante" (Braidotti, 2009, citada en Piedrahita, 2015, p. 42). He aquí la biografización de la vida como estímulo para el encuentro con los otros, la reinvención como diferencia, como subjetivación política.

\section{Segunda interpretación: la recurrencia de un lenguaje metafórico en las prácticas de escritura digital juvenil}

El uso de un lenguaje metafórico en las prácticas escriturales digitales es una recurrencia en las interacciones comunicativas de Johanna y Edward. Recordemos que lo metafórico alude al uso de un lenguaje no literal, que se produce por fuera de lo lingüísticamente formal, para devenir como un lenguaje subjetivo, imaginativo, inestable, dinámico y fundamentalmente contextual, en un tiempo y espacio determinados:

La metáfora no crea nuevas palabras para dar cuenta de los múltiples objetos y fenómenos de la realidad, sino que organiza las existentes de tal forma que brinda una nueva visión de estas y les otorga nuevos sentidos a partir del uso que de estas se hace. (Fajardo, 2007, p. 107).

Es un lenguaje del combinar, acomodar y reinventar que, si bien se vale de lo dado, lo aprovecha para desordenar y desmontar las palabras y sus significados asignados por un otro (cultura, sociedad, especialistas, entre otros). Es un lenguaje construido subjetiva e intersubjetivamente, y con una configuración polisémica que desplaza la objetividad racional del lenguaje literal.

En las prácticas escriturales digitales de Johanna y Edward, el uso metafórico se construye no solo a partir de la palabra escrita, sino a través de videos, música, fotografías, imágenes y emoticonos, que son usados a manera de rizoma, y lo hacen con el fin de animar, sostener y afectar las relaciones que llevan a cabo:

Con mi novio utilizamos mucho por ejemplo si nos mandamos mensajes de notas de voz, utilizamos voces diferentes a como yo te estoy hablando ahorita, entonces digamos que eso solo es entre nosotros, y por ejemplo muchos corazoncitos, todos los estilos de emoticonos, nos escribimos muchas veces con emoticonos y a todas las palabras les ponemos algo. Nos mandamos las fotos de Teresa, que es la gata, entonces si él está trabajando yo le mando "Teresa hizo tal cosa", y entonces le mando la foto o cualquier cosa, entonces él me pone la carita de un gato que tiene los ojos de corazón entonces ya se sabe que le encantó la foto, entonces es como un código, porque pues igual no se puede poner a chatear entonces ah vio la foto corazoncito y ya. Los emoticonos ya tienen su código, exacto. (Johanna, 25 años).

La producción de las escrituras digitales de Johanna evoca sentimientos, deseos y expresiones afectivas que le generan una sensación de bienestar y de autonomía al escribir a su manera, liberándose de la objetividad y la racionalidad que en otros momentos plantea el uso del lenguaje literal. Tales escrituras contribuyen, según ellos, a mantener el contacto y una idea de presencia que se hace tangible a través de sonidos, emoticonos y mensajes de voz. Esto nos lleva a plantear que, si bien son escrituras producidas en los nuevos dispositivos de poder, también nos presentan la agencia y experimentación subjetiva que están viviendo los jóvenes con respecto a la escritura, lo cual posibilita nuevas preguntas para su enseñanza en el tiempo actual.

Hoy, al contrario de lo que sucedía en la sociedad moderna, es la emoción (la alegría, tristeza, amor, miedo, angustia, ansiedad, preocupación, rabia, entre otras) la que nos trae la escritura como posibilidad de relación; esto nos puede llevar, y sobre todo al pensar en una pedagogía de la escritura, a recomenzar otra historia cuyo inicio sea la pregunta por "lo que nosotros en nuestro mundo estamos dispuestos a aceptar, rechazar o modificar, tanto en nosotros mismos como en nuestras relaciones" (Foucault, 1980, citado en Cubides, 2006, p. 39). Es justamente 
desde la sensibilidad emocional que comenzamos a ser otros y a usar distintas técnicas (entre ellas la escritura) para transformarnos - afirmativamenteen aquello que deseamos.

Como lo hemos venido nombrando, subjetivarse políticamente es des-identificarse con lo previamente establecido, con el orden dado por otro y del cual es necesario sustraerse para ser de otra manera y poder devenir diferente. De ahí que las escrituras de estos jóvenes subviertan un lenguaje que, en palabras de Rancière (2006), ha sido concedido por un orden policial, y conviertan las palabras en polifonías biográficas. Pero quizás lo más llamativo es que la escritura producida en los espacios digitales se esté convirtiendo en una técnica de sí, en una manera de autoconstituirse en lugar de ser sujetados por técnicas de dominación (Cubides, 2006). Aunque el efecto pharmakón siempre estará presente, la idea de que el sujeto se produzca a sí mismo en relación con otros será mucho más potente que la obediencia forjada en el deber ser de la escritura que imperó en la sociedad del siglo xIx.

Por lo anterior, vemos que la subjetividad política de estos jóvenes deviene biográfica y emocional, no solo por la influencia de las condiciones técnicas de los dispositivos digitales, sino por las decisiones que toman en relación con la capacidad de agencia que desean producir, pues la autogestión, el diseño, la difusión y la socialización se conectan con sus sentidos de vida, con aquello que quieren y acarician ser, y en torno a lo cual se crea una experiencia política como oportunidad de encuentro/desencuentro en la que los gustos y proyecciones de sí mismo se perciben como el inicio de una apuesta colectiva.

De igual manera, la significación que toma la escritura digital en relación con la producción de subjetividad política se anuda a las posibilidades que la hipermedialidad e hipertextualidad ofrecen, en la medida que la multiplicidad de códigos sonoros, visuales e icónicos — con la adecuación de estos a intenciones comunicativas (Ferrés, 2014) - estaría afectando una experiencia de sí (agencia y deseo) y el tejido de lazos sociales teñidos - mayormentepor los universos emocionales de cada quien. Tal afectación no solo se daría por el placer que implica para los jóvenes compartir e interactuar, sino por la capacidad de reacción que causan los contenidos y que los lleva, según Edward y Johanna, a desear, a querer estar conectados, expectantes, como condición de sentirse vivos:

Sigo en Facebook varias páginas de arquitectura, entonces cada vez que veo estos tipos, como que lo publico, le pongo me gusta, lo comparto como para que se vuelva más conocido para la gente, como son nuevas tecnologías son muy poco conocidas, entonces trato de compartirlas. También llego a la universidad, por ejemplo, y le digo a alguien "ay, hoy vi en Facebook tal cosa, me parece muy chévere", como eso, y sacar esa información, o también para trabajos, como veo eso y lo incluyo en mi trabajo para poderlo exponer acá, sacar toda esa información de ahí; estoy pendiente de quién dice algo, de comentarios que los compañeros hacen, de si publican nuevas cosas que me interesan. (Edward, 23 años).

Johanna, por su parte, complementa:

Todo el día [estoy conectada], realmente todo el día, y digamos que puedo decir que en el único momento en el que no es porque estoy durmiendo o realmente estoy muy ocupada, pero son lapsos de ocupación muy cortos, porque, por ejemplo, las clases duran de dos a tres horas entonces, si de verdad es que no puedo revisar el celular en dos o tres horas, termina la clase y lo reviso, entonces uno está conectado todo el tiempo. O por ejemplo si estoy en ensayo en una academia donde trabajo, entonces tampoco en esas dos horas de clase tengo la posibilidad de revisarlo, pero igual lo estoy usando, porque, por ejemplo, el celular en la clase me sirve para grabar a las niñas y que ellas se miren y después uno hace retroalimentación de la coreografía y ellas se dan cuenta de muchas cosas viéndose ya desde otro punto; además, cuando uno ve por ejemplo el baile o una coreografía en vivo es diferente a cuando uno lo ve en video porque se pierde la fuerza, se pierden muchas cosas y uno ve más los errores en el video que en vivo, entonces eso sirve mucho. O la música, ahí reproduzco la música y descargo las canciones y todo, entonces, básicamente es todo el día que uno está conectado, todos los días, los fines de semana, todo el tiempo. (Johanna, 25 años). 
Las escrituras digitales de estos jóvenes como procesos de relación (conexión digital permanente) se anidan a intereses, gustos y necesidades de vida, con sentidos prácticos de realización que logran encajar - de forma satisfactoria - con la instantaneidad, rapidez y facilidad que ofrecen, según ellos, las tecnologías digitales. Escriben porque sus afectos los inspiran, porque sus proyectos académicos y personales, y curiosidades de la vida así lo demandan. Y lo hacen para divertirse, para estar menos solos, para sentir que existen para alguien, que no están abandonados a sí mismos, y para darse cuenta de que, por tanto, en un espacio digital siempre habrá otro que dice algo.

Sería muy interesante trasladar al ámbito de la escuela estas virtudes digitales para la escritura; proponer proyectos que toquen las fibras emocionales de los estudiantes, y de ahí aventurarse a conocer y a curiosear lo que a los chicos les interesa, lo que les produce alegría, ganas de saber, deseo. Eso sí, no se trata de dejar que cada quien lo haga como pueda, con descuidos pedagógicos de por medio, sino con un compromiso por hacer ver en las escrituras producidas condiciones políticas de comprensión sobre lo dicho, de responsabilidades y construcciones éticas en las que escribir para los otros subvierte el individualismo como técnica dominante del momento actual, a la vez que emancipa a partir de la conciencia que la escritura como producción de sí genera.

\section{Reflexiones y desafíos para una pedagogía de la escritura en el contexto educativo}

Las interpretaciones que Johanna y Edward nos permitieron elaborar a través de sus producciones digitales nos insinúan cierta celebración tecnológica que podría poner en entredicho la sujeción de los dispositivos actuales. No obstante, lo que deseamos rescatar a partir de lo analizado no es tanto el uso de las tecnologías per se, sino la capacidad de agencia y experimentación subjetiva que estos jóvenes nos dejan como posibilidades para un trabajo pedagógico de la escritura en la escuela. Más allá de lo que las tecnologías están permitiendo realizar, de lo que se trataría es de ver en las acciones descritas cómo subvierten dominios, cómo se desplazan, cómo transitan hacia la construcción de otros posibles, en los que el deseo de relación pone en juego lo biográfico y el lenguaje metafórico como configuraciones de vida en lo digital.

Las tecnologías digitales los seducen porque es en estos espacios donde pueden construir saberes a su manera, seguir a personas que pueden aportar a sus intereses, formar vínculos con extraños con los que se juntan a partir de luchas comunes, compartir información, reír, conversar, sorprenderse, arriesgarse, escuchar, aburrirse, indignarse. Es la producción de sí en correlación con los otros lo que logra enlazar a los jóvenes con los espacios digitales.

Lo anterior, llevado a nuestro interés por la vigencia de una enseñanza de la escritura en la escuela, nos revierte las intencionalidades políticas de esta traídas desde la modernidad, en tanto que hoy la escritura se descentra como dispositivo civilizatorio y estrictamente racional, para constituirse como medio de expresión derivado - mayormente - de la emocionalidad que, para estos jóvenes, implica un mostrarse, un hacerse ver, que no funciona con la idea de prestigio o distinción política (tal como sucedía en la modernidad), ni mucho menos con la desaparición de las pasiones, sino con la idea del sentir y emocionarse desde sí y con los otros. No podemos desconocer esta cuestión como técnica de dominio que utiliza el capitalismo globalizado para capturar y atraer las mentes de todos a partir de estímulos (estéticos e informativos) emplazados en la pantalla. Aun así, la subjetividad juvenil y la experiencia escritural devienen diferentes, muy distantes de las maneras de ser del siglo xIX.

Deseamos que, a partir de las interpretaciones anteriores, podamos develar otra manera de trabajo pedagógico, es decir, que la enseñanza de prácticas escriturales no sea siempre la gestión sobre el canon gramatical y textual que nos ha dicho cómo se debe escribir correctamente para participar en 
el ámbito social y para desterrar las emociones y pasiones como torpezas de la racionalidad ilustrada (Bermúdez, 2015a). Se trataría más bien de la construcción de experiencias escriturales que convoquen a la emancipación como proceso subjetivante de una realización singular y colectiva, con el fin tanto de subvertir las formas de dominio actuales, como de cuestionar relaciones de poder, las opresiones que hemos permitido sobre nosotros mismos. Esto debe darse a través de situaciones de escritura en las que el personaje principal sea el sí mismo en relación con amigos, familia, escuela y sociedad, además con posibilidades expresivas que ofrecen las tecnologías digitales como videos, imágenes, música y fotos. Es una escritura digital en la que el recuerdo tiene que decir algo, sobre todo en lo tocante a la posibilidad de rechazar, aceptar y modificar lo que somos.

Desde lo que Johanna y Edward nos manifestaron, creemos que si la escritura se acerca a los fueros internos, a las intuiciones y a los deseos de las personas, las complicidades pueden llegar más pronto. La escritura, social y escolarmente, se ha mostrado muy ajena, pedante y a veces hasta inalcanzable. Ha sido expuesta como una técnica de poder y como privilegio de unos pocos: de los “inteligentes", literatos, burgueses, etcétera; con ella se ha realizado un reparto de lo sensible (Rancière, 2006) que ha estimulado la exclusión, y por ello muchas personas se resisten a ella, no la ansían.

En tiempos en los que no hay una estabilidad estatal que articule y jalone la producción de subjetividad y la escritura como condición de esta (Corea y Lewkowicz, 2004), la homogenización a la que sigue aspirando la escuela ya no es necesaria, mucho menos la idea de que escribir es un requisito para ser civilizados. Creemos que uno de los desafíos hoy es intentar ser más confiados en las historias de vida o biografías de los estudiantes, no rehuir la mirada de lo que ellos expresan de sus realidades, no banalizar lo personal, sino aprovechar las fugas que realizan en Internet, las encrucijadas que resuelven, lo que comparten, los relatos, y la música que los subjetiva y los hace valorar la vida.
Así, desde la escuela, podríamos contribuir a la configuración de subjetivaciones políticas atravesadas por prácticas pedagógicas de escritura digital, con un carácter diverso, plural, con uso de formas de expresión variadas, con funciones comunicativas distintas, con una idea del compartir errante, con posibilidades de reinventar las palabras y sus significados y con un aprendizaje que puede configurarse entre todos y para todos. Este desafío nos desconectaría del uso instrumental que siguen teniendo las tecnologías digitales en las aulas colombianas (Rozo y Bermúdez, 2014), pero además nos abriría a un diálogo constructivo y productivo, pues, al decir de Freire (2012),

Cuanto mayor va siendo la importancia de la tecnología en la actualidad más se afirma la necesidad de una vigilancia ética rigurosa sobre sus alcances; de una ética al servicio de la gente, de su vocación ontológica, la de ser más, y no una ética estrecha y perversa como la del lucro o la del mercado. (p. 129).

\section{Referencias}

Agamben, G. (2001). Medios sin fin. Notas sobre la política. Valencia: Pre-textos.

Amador, J. C. (2012). Infancias, subjetividades y cibercultura: Noopolítica y experiencia de sí. Revista Científica, (15), 12-29. Recuperado de: http://revistas.udistrital.edu.co/ojs/index.php/revcie/article/ view/3935

Arfuch, L. (2002). El espacio biográfico. Dilemas de la subjetividad contemporánea. Buenos Aires: Fondo de Cultura Económica.

Bermúdez, M. M. (2015a). Escritura(s) y modos de subjetivación: Del ciudadano moderno a la subjetividad juvenil contemporánea. Enunciación, 20(1), 56-67.

Bermúdez, M. (2015b). Investigación cualitativa, subjetividad política-juvenil y espacios tecnomediados. En Marco de las XIV Jornadas \& II Congreso Internacional del Maestro Investigador. Universidad Pontificia Bolivariana, 1-21.

Bermúdez, M. M. (2014). Jóvenes, prácticas políticas y mediaciones tecnológicas. Una aproximación desde los estudios realizados en la última década (2000-2013). Estado del arte: Universidad Pedagógica Nacional, Doctorado Interinstitucional. 
Bonvillani, A. (2014). Saberes apasionados: Horizontes de construcción de conocimiento de las subjetividade(s) política(s). En C. Piedrahita, A. Días y P. Vommaro (comps.), Acercamientos metodológicos a la subjetivación política: Debates latinoamericanos (pp. 83-100). Bogotá: Universidad Distrital Francisco José de Caldas y Clacso.

Cassany, D. (2012). En-línea. Leer y escribir en la red. Barcelona: Anagrama.

Castro-Gómez, S. (2009). Noopolítica y sociedades de control: Las subjetividades contemporáneas en Maurizio Lazzarato. En J. Martínez y F. Neira (eds.), Cátedra Lasallista: Miradas sobre la subjetividad (pp. 21-38). Bogotá: Universidad de la Salle.

Corea, C. y Lewkowicz, I. (2004). Pedagogía del aburrido. Escuelas destituidas y familias perplejas: Buenos Aires: Paidós Educador.

Cubides, H. (2006). Foucault y el sujeto político. Ética del cuidado de sí. Bogotá: Siglo del Hombre Editores y Universidad Central-Iesco.

Chartier, R. (2007). Hay una tendencia a transformar todos los textos en bancos de datos. Lectura $y$ Tecnología. Revista la Biblioteca, 6, 10-28.

De Certeau, M. (1985). La invención de lo cotidiano. I. Artes de hacer. México: Universidad Iberoamericana.

Deleuze, G. (2006). Post-scriptum de las sociedades de control. En Conversaciones (pp. 265-286). Valencia: Pretextos.

Delgado, J. M. y Gutiérrez, J. (1995). Métodos y técnicas cualitativas de investigación en ciencias sociales. Madrid: Síntesis.

Escobar, M. (2012). Del "proyecto de vida" al "guerreo". Avatares de la producción de subjetividades juveniles contemporáneas. En F. Rojas, G. Muñoz y L. Corredor (eds.), Jóvenes \& adultos. Una pedagogía del encuentro (pp. 82-93). Bogotá: Pontificia Universidad Javeriana.

Fajardo, L. A. (2007). La metáfora, un recurso en la formación de pensamiento. Praxis Educativa (Arg), 11(11) 103-112. Recuperado de: http://www.redalyc. org/articulo.oa? $\mathrm{id}=153112899010$

Férres, J. (2014). Las pantallas y el cerebro emocional. Barcelona: Gedisa.

Foucault, M. (1996). Tecnologías del yo. Barcelona: Paidós.

Foucault, M. (1999). Estética, ética y hermenéutica. En Obras esenciales, vol. III. Barcelona: Paidós.
Escrituras contemporáneas y procesos de subjetivación política-juvenil. Reflexiones y desafíos para una pedagogía de la escritura en el contexto educativo Mónica María Bermúdez G.

Freire, P. (2012). Pedagogía de la indignación. Cartas pedagógicas en un momento revuelto. Buenos Aires: Siglo xxi editores.

Gómez, R. (2010). Procurarse sentido en la ciudad contemporánea: jóvenes y nuevos repertorios tecnológicos (tesis inédita de doctorado). Universidad Pedagógica Nacional, Bogotá, Colombia.

González, B. (1994). Escritura y modernización: la domesticación de la barbarie. Revista Iberoamericana, 60(166), 109-124.

Hine, C. (2002). Etnografía virtual. Barcelona: Ed. uoc.

Jenkins, H. (2008). Convergence culture. La cultura de la convergencia de los medios de comunicación. Barcelona: Paidós.

Lazzarato, M. (2006). Políticas del acontecimiento. Buenos Aires: Tinta Limón.

Levy, P. (2007). Cibercultura. Barcelona: Anthropos.

Lipovestky, G. (2002). La era del vacío. México: Anagrama.

Marcus, G. (2001). Etnografía en/del sistema mundo. El surgimiento de la etnografía multilocal. Alteridades, 11(22), 111-127.

Mejía, M. (2004). La globalización educativa reconstruye el sujeto de la modernidad. En M. Laverde, G. Daza y M. Zuleta (eds.), Debates sobre el sujeto. Perspectivas contemporáneas (pp. 149-177). Bogotá: Universidad Central/Diuc/Siglo del Hombre.

Muñoz, G. (2007). La comunicación en los mundos de vida juveniles. Revista Latinoamericana de Ciencias Sociales, Niñez y Juventud, 5(1), 1-18.

Piedrahita, C. (2015). Subjetivaciones políticas y pensamiento de la diferencia. Bogotá: Universidad Distrital Francisco José de Caldas/Clacso.

Rancière, J. (2006). Política, policía y democracia. Santiago de Chile: Lom.

Rodríguez, T. (2000). Textos e hipertextos. Aula abierta, (75), 3-26.

Rozo, C. y Bermúdez, M. (2014). ¿Cómo enseñan los maestros en el área de Tecnología e Informática? Análisis de las propuestas del Premio Compartir al Maestro. Bogotá: Fundación Compartir.

Rueda, R. y Calonje, P. (2014). El método biográfico. En R. Parra y E. Castañeda, Los maestros colombianos, tomo 1 (pp. 105-142). Ibagué: Convenio Andrés Bello, Universidad Externado de Colombia y Universidad de Ibagué. 
Rueda, R. (2011). De los nuevos entramados tecnosociales: Emergencias políticas y educativas. Folios, $33,7-22$.

Rueda, R. (2012). Sociedad de la información y el conocimiento: tecnicidad, phármakon e invención social. Nómadas, 36, 43-55.

Serres, M. (2013). Pulgarcita. Buenos Aires: Fondo de Cultura Económica.
Sibilia, P. (2008). La intimidad como espectáculo. Buenos Aires: Fondo de Cultura Económica.

Tassin, E. (2012). De la subjetivación política. Althusser/ Ranciere/Foucault/Harent/Deleuze. Revista de Estudios Sociales, 43, 36-49.

\section{Para citar este artículo}

Bermúdez, M. (2017). Escrituras contemporáneas y procesos de subjetivación política-juvenil. Reflexiones y desafíos para una pedagogía de la escritura en el contexto educativo. Folios, (46), 67-82. 